3 Mahadevan MS, Ooi DS. Changes in free thyroxin (FT 4 values of clinical assays gammacoat two-step assay. Clin Chem 1988;34:987.

4 Hunter WM, Budo PS. Circulating antibodies to ovine and bovine immunoglobulin in healthy subjects: a hazard for immunoassays. Lancet 1980;ii:1136.

5 Klug TL, Green PJ, Zurawski VR, Davis HM. Confirmation of a false-positive result in CA125 immunoradiometric assay caused by human anti-idiotypic immunoglobulin. Clin Chem 1988;34:1071-6.
6 Hashimoto T, Ohba N, Matubara F. Discordant CA125 measurements in normal healthy women. Clin Chem 1990; 36:1377-8.

7 Banfi G, Casari E, Murone M, Bonini P. Discrepancies among commercial kits for assaying growth hormone. Clin Chem 1990;36:402.

8 Smith MC, Brown ME, Morel JH, Woodward SC. Erroneous test results obtained with the Tandem-E TSH kit. Clin Chem 1988;34:1946-7.

\title{
Helicobacter pylori serology using specimens collected on filter paper
}

\author{
Z Huang, B Dwyer, J Kaldor
}

Jiangsu Province Hospital, Nanjing, People's Republic of China

Z Huang

Fairfield Infectious Diseases Hospital, Yarra Bend Road, Fairfield, Australia, 3078

B Dwyer

J Kaldor

Correspondence to Mr J Kaldor

Accepted for publication 16 August 1990

\begin{abstract}
A simple method for the collection of blood specimens on filter paper for serology of Helicobacter pylori was devised. Blood was freshly applied to small Whatman $3 \mathrm{~mm}$ filter paper and allowed to dry. Serological activity, as measured by reactivity to $H$ pylori antigens (AMRAD, Australia), was retained after storage for one month at both room temperature and at $4^{\circ} \mathrm{C}$. This technique eliminates formal venepuncture, separation of sera, and arduous packaging of specimens to be sent to the laboratory.
\end{abstract}

Seroepidemiological surveys are often rendered more difficult because of a lack of facilities for the collection and transportation of liquid serum specimens and because of difficulties with venepuncture, especially in infants. Specimen samples collected and dried on filter paper overcome these disadvantages and require only a minute volume of specimen, easily collected directly from an ear lobe or finger prick.

Samples collected and dried on filter paper have been used for the detection of markers of hepatitis B. ${ }^{1}$ phenylketonuria, ${ }^{2}$ separation of haemoglobin $\mathrm{S},{ }^{3}$ detection of antibodies to human immunodeficiency virus, ${ }^{4}$ and the storage of cerebrospinal fluid. ${ }^{5}$

\section{Methods}

Samples from 20 patients (10 infected patients and 10 non-infected patients), assessed by endoscopy, histology, Gram stain and culture were used to define the conditions of testing for comparison of conventional liquid serum tests and tests on specimens dried on filter paper. The samples were allowed to dry completely at room temperature and then stored in plastic bags (figure). Aliquots of fresh samples were applied in volumes of $10 \mu \mathrm{l}$ (serum) and $20 \mu \mathrm{l}$ (whole blood) to strips of filter paper.

Whatman $3 \mathrm{~mm}$ filter paper (No 3030917) was used. The filter paper was cut into $40 \mathrm{~mm}$ $\times 5 \mathrm{~mm}$ strips; one end of each strip was used for identification and the other was used for the specimen. For this experiment one lot of the filter paper dried specimens was kept at $4^{\circ} \mathrm{C}$ and the other at room temperature $\left(22^{\circ} \mathrm{C}\right)$. The stability of antibody titre in the dried specimens was tested at weekly intervals for four weeks. The results were compared with those obtained from a collection of multiple aliquots of the same serum kept at $-70^{\circ} \mathrm{C}$ until thawed on the day of testing.

Statistical comparison was made using paired $t$ tests, the Wilcoxon sign test, the Mann-Whitney $U$ test and one way analysis of variance.

Specimens from 83 healthy people enrolled in a seroepidemiological study of rickettsial

\begin{tabular}{|c|c|c|c|c|c|c|c|c|c|c|}
\hline \multirow[b]{3}{*}{$\begin{array}{l}\text { Mean negative } 15 \text { days } \\
\text { Mean negative } 30 \text { days } \\
\text { Mean positive } 15 \text { days } \\
\text { Mean positive } 30 \text { days }\end{array}$} & \multirow{2}{*}{\multicolumn{2}{|c|}{$\begin{array}{l}\text { Control serum } \\
\text { specimens }\end{array}$}} & \multicolumn{8}{|c|}{ Filter paper specimens } \\
\hline & & & \multicolumn{2}{|c|}{ Serum $4^{\circ} C$} & \multicolumn{2}{|c|}{ Serum $R T$} & \multicolumn{2}{|c|}{ Blood $4^{\circ} \mathrm{C}$} & \multicolumn{2}{|c|}{ Blood RT } \\
\hline & $\begin{array}{r}1 \cdot 0 \\
1.0 \\
11 \cdot 4 \\
11.6\end{array}$ & $\begin{array}{l}(0.3) \\
(0.4) \\
(3.9) \\
(3.9)\end{array}$ & $\begin{array}{r}1.0 \\
0 \cdot 8 \\
11 \cdot 3 \\
11.0\end{array}$ & $\begin{array}{l}(0 \cdot 4) \\
(0 \cdot 3) \\
(4 \cdot 4) \\
(3 \cdot 7)\end{array}$ & $\begin{array}{r}0.9 \\
1.0 \\
12 \cdot 4 \\
8.9\end{array}$ & $\begin{array}{l}(0 \cdot 3) \\
(0 \cdot 3) \\
(4 \cdot 8) \\
(3 \cdot 6)\end{array}$ & $\begin{array}{r}1 \cdot 0 \\
1.0 \\
12 \cdot 4 \\
13 \cdot 7\end{array}$ & $\begin{array}{l}(0 \cdot 2) \\
(0 \cdot 4) \\
(4 \cdot 5) \\
(4 \cdot 6)\end{array}$ & $\begin{array}{r}0.9 \\
1 \cdot 0 \\
12 \cdot 3 \\
13 \cdot 1\end{array}$ & $\begin{array}{l}(0 \cdot 3) \\
(0 \cdot 4) \\
(4 \cdot 3) \\
(4 \cdot 5)\end{array}$ \\
\hline
\end{tabular}

RT = Room temperature 
infections in south eastern Australia were used to compare the two methods. At the time of collection, $7 \mathrm{ml}$ of whole blood was drawn into Exetainer plain tubes (Labco Ltd, England). Aliquots of $20 \mu \mathrm{l}$ of the whole blood were immediately applied to labelled filter paper strips and allowed to absorb before transference to individually labelled plastic strip bags for storage at room temperature until samples were tested five to 10 days later.

Pooled negative control serum supplied by AMRAD was also applied to filter paper. Anti-IgG antibodies to Helicobacter pylori were measured with the AMRAD IgG kit (AMRAD Corporation, Hawthorn, Victoria, Australia).

The AMRAD kit is based on the previously published method. ${ }^{6}$ Antigen used in the kit is derived from a sonicate of the whole organism. The sample buffer has a $\mathrm{pH}$ of $7 \cdot 3$. Horseradish peroxidase conjugated sheep anti-human IgG is obtained commercially.

For the direct estimation of serum antibodies $10 \mu \mathrm{l}$ of serum was mixed with $4 \mathrm{ml}$ of sample buffer provided in the kit and then the tests proceeded according to the manufacturer's instructions. Briefly, $100 \mu \mathrm{l}$ of the diluted serum ( 1 in 400 ) was placed into duplicate microtitre wells, incubated for one hour at room temperature at $37^{\circ} \mathrm{C}$, washed and then anti-IgG conjugate was added. After a further one hour of incubation and subsequent washing the colour reaction was developed over 30 minutes with the addition of substrate. The activity was expressed as the optical density (at $450 \mathrm{~mm}$ ) divided by the mean of optical density of the negative control. A positive result was regarded as $\geqslant 3$ and a negative as $\leqslant 2$, as the pedigreed sera conformed perfectly to this classification (table). Other reagent combinations could be used satisfactorily, provided the relevant concen-

Method of application and storage of specimens on filter paper. trations and reference range have been determined.

For both whole blood and serum specimens dried on filter paper the sample was eluted overnight at $37^{\circ} \mathrm{C}$ in $4 \mathrm{ml}$ of kit specimen buffer, then agitated for two hours at room temperature. Then assay procedure was identical with the conventional serum estimation.

\section{Results}

DEVELOPMENT OF ASSAY

The mean titres of the 10 negative and 1.0 positive specimens stored at $4^{\circ} \mathrm{C}$ and room temperature for 15 and 30 days are shown in the table. During the first 15 days of storage no significant loss of activity occurred when compared with the frozen fresh specimens, irrespective of the storage method. After 30 days serum specimens kept on filter paper and stored at room temperature incurred an average loss of activity of $25 \%$ relative to frozen fresh specimens $(t=4.69$, $p=0.0012$ ). Best results were obtained with whole blood, which remained stable for this interval at both temperatures. Blood specimens gave slightly higher results than control serum specimens. This relates to the $20 \mu \mathrm{l}$ sample volume of whole blood with a haematocrit of about $40 \%$. Correction for this by multiplying by $5 / 6$ normalises the results to $10 \mu$ l volume of serum.

The statistical correlation of different specimens and storage methods after 30 days for the 10 positive specimens with the control serum further confirmed the first observation of the instability of the serum kept on filter papers at room temperature.

\section{FRESH FIELD SPECIMENS}

Of the 83 specimens obtained in the field 13 had increased antibody titres. The results of serum and filter paper specimens were in complete agreement. The mean of the 13 positive results for serum specimens was 8.0 and for filter paper collected blood specimens it was $8 \cdot 4(t=0.529, \mathrm{p}=0 \cdot 8)$.

\section{Discussion}

We have shown that specimens of blood and serum collected and dried on filter paper and then stored for 15 days at $4^{\circ} \mathrm{C}$ or room temperature show similar antibody titres to conventionally collected and stored specimens. Blood specimens stored at $4^{\circ} \mathrm{C}$ or room temperature on filter paper for 30 days did not show any significant loss of activity for whole blood specimens. Serum specimens dried on filter paper and kept at $4^{\circ} \mathrm{C}$ incur only a minimal loss of activity. The same specimens kept at room temperature incur a variable and unpredictable loss of activity of up to $25 \%$. We cannot explain why whole blood specimens show greater stability except that whole blood may contain some stabilising factor(s). In most circumstances 15 day stability should be sufficient to permit the mailing of speci- 
mens to the laboratory. In the test presented here dried specimens were eluted in $4 \mathrm{ml}$ of sample buffer and yet only $200 \mu \mathrm{l}$ is used for $H$ pylori antibody estimation. This gives the opportunity for the unused eluted portion to be used to measure other antibodies as the sample eluted can be kept for at least one week at $4^{\circ} \mathrm{C}$ without loss of activity (results not shown).

Whole blood dried on filter paper provides an ideal method of specimen collection for an expanding range of tests applicable to human health and disease. The stability and reproducibility of the results are comparable with those obtained with whole serum but without the inconvenience of that material.
This filter helper procedure can also be applied to other serological methods.

1 Zhuang H, Coulepis AG, Locarnini SA, Gust ID. Detection of markers of hepatitis $B$ infection in serum dried onto filter paper: an application to field studies. Bull $W H O$ 1982;60:783-7.

2 Guthrie R, Susi A. A simple phenylamine method for detecting phenylketonuria in large populations of new born infants. Pediatrics 1963;32:338-43.

3 Thielmann K, Moreina Aquino A. Whole blood samples dried and stored on filter paper as substrate for the dried and stored on filter paper as substrate for the electrophoretic separation of haemoglobin $S$ from haemoglobin A: A screening procedure. Clin Chim Acta

4 Farzadegan H, Quinn T, Polk F. Detecting antibodies to human immunodeficiency virus in dried blood or filter human immunodeficiency virus in

paper. Infect Dis 1987;155:1073-4.
5 Garcia E, Sotelo J. Storage of cerebrospinal fluid on paper. Lancet 1989; ii: 1046.

6 Kaldor J, McCarthy P, Watson J, Dwyer B. Immune response to Campylobacter pyloridis in patients with peptic ulceration. Lancet 1985;i:269.

\title{
Laboratory detection of ciprofloxacin resistant Neisseria gonorrhoeae
}

\author{
A Turner, A E Jephcott, K R Gough
}

\begin{abstract}
During 1989 and 1990 strains of Neisseria gonorrhoeae with reduced susceptibility to ciprofloxacin were isolated in laboratories across the United Kingdom. Treatment failures were associated with some of these infections. These strains were detected by quantitative susceptibility testing because the zone of inhibition around $5 \mu \mathrm{g}$ ciprofloxacin discs shows little decrease in size even with those that are the most resistant. This study determined that strains with reduced susceptibility to ciprofloxacin (MIC of $\geqslant 0.05 \mathrm{mg} / 1$ ) produced no zone of inhibition around a commercially available disc containing $30 \mu \mathrm{g}$ of nalidixic acid. Ciprofloxacin sensitive (MIC of $<0.05 \mathrm{mg} / 1$ ) strains, however, grew with a large zone (>21 mm) around this disc. These observations suggest that laboratories could adopt this disc test to detect those strains for which ciprofloxacin is not appropriate treatment.
\end{abstract}

Ciprofloxacin has good in vitro activity against most strains of Neisseria gonorrhoeae $e^{1-3}$ and consequently has been increasingly used as a first line treatment for gonorrhoea. Strains with decreased sensitivity (MIC of $\geqslant 0.05 \mathrm{mg} / \mathrm{l}$ ), however, have been detected with increasing frequency in the past year and treatment failures with ciprofloxacin have been associated with some of these infections. ${ }^{45}$

It would clearly be beneficial if these strains could be detected by routine testing in all laboratories. Unfortunately, agar dilution quantitative sensitivities are labour intensive and are not usually practicable in a busy laboratory. At the Gonococcus Reference Unit (GRU), however, a simple qualitative test has been developed which seems to overcome this difficulty and could facilitate screening for these organisms.

\section{Method and results}

All gonococci received by the GRU are sensitivity tested by the agar dilution method to five antibiotics including ciprofloxacin. From these isolates representative ciprofloxacin sensitive strains, with a range of MICs, and all 25 strains with reduced sensitivity available to us (including isolates with ciprofloxacin MICs of up to $0.50 \mathrm{mg} / \mathrm{l}$ ), were selected for this study. Their sensitivity was evaluated in a simple antibiotic disc test on heated blood agar using commercially available ciprofloxacin $(5 \mu \mathrm{g})$ and nalidixic acid $(30 \mu \mathrm{g})$ discs. After overnight incubation the diameters of the zones were measured using calipers.

All less sensitive strains show little decrease in zone of inhibition around the $5 \mu \mathrm{g}$ ciprofloxacin disc, even those with the highest MICs (fig 1). The data in fig 2, however, show that the zone of inhibition around the nalidixic acid disc was reduced to zero for strains with ciprofloxacin MICs greater than $0.025 \mathrm{mg} / \mathrm{l}$, whereas a large $(>21 \mathrm{~mm}$ in diameter) inhibition zone around this disc was invariably present when sensitive strains (MIC of $\leqslant 0.025 \mathrm{mg} / \mathrm{l}$ ) were tested. 